\title{
Prevalence and Correlates of Pregnancy Self- Testing Among Pregnant Women Attending Antenatal Care in Western Kenya
}

Nina Njeri Nganga

University of Washington https://orcid.org/0000-0002-4284-301X

Julia Dettinger

University of Washington

John Kinuthia

University of Washington

Jared Baeten

University of washington

Grace John-Stewart

University of Washington

Laurén Gómez

University of Washington

\section{Ben Ochieng}

University of Nairobi

Mary Marwa

Kenyatta National Hospital

Kenneth Mugwanya

University of Washington

Melissa Mugambi ( $\sim$ mugambi@uw.edu )

University of Washington https://orcid.org/0000-0001-8875-5528

Jillian Pintye

University of Washington

\section{Research article}

Keywords: Antenatal care, pregnancy self-testing, western Kenya, pregnancy uncertainty

Posted Date: December 13th, 2021

DOI: https://doi.org/10.21203/rs.3.rs-78174/v2 
License: (c) (i) This work is licensed under a Creative Commons Attribution 4.0 International License. Read Full License

Version of Record: A version of this preprint was published at PLOS ONE on November 12th, 2021. See the published version at https://doi.org/10.1371/journal.pone.0258578. 


\section{Abstract}

In sub-Saharan Africa little is known about how often women use pregnancy self-tests or characteristics of these women despite evidence that pregnancy self-testing is associated with early antenatal care (ANC) initiation. Understanding the characteristics of women who use pregnancy self-tests can facilitate more targeted efforts to improve pregnancy testing experiences and entry into the ANC pathway. We conducted a cross-sectional survey among pregnant women enrolling in a pre-exposure prophylaxis (PrEP) implementation study to determine the prevalence and factors associated with pregnancy selftesting among women in western Kenya. Overall, in our study population, $17 \%$ of women obtained a pregnancy self-test from a pharmacy. Pregnancy test use was higher among employed women, women with secondary and college-level educated partners, and women who spent 30 minutes or less traveling to the maternal and child health $(\mathrm{MCH})$ clinic. The most reported reasons for non-use of pregnancy selftests included not thinking it was necessary, lack of knowledge, and money to pay for the test. Future research should focus on understanding the knowledge and attitudes of women toward pregnancy selftesting as well as developing community-based models to improve access to pregnancy testing and ANC.

\section{Introduction}

The World Health Organization (WHO) recommends that pregnant women should initiate the first antenatal care (ANC) visit in the first trimester of pregnancy because early ANC access is central to identifying pregnancy complications and managing pre-existing conditions[1]. However, in western Kenya, less than $20 \%$ of pregnant women are estimated to present for ANC in the first trimester[2]. Barriers to early initiation of ANC due to uncertainty of pregnancy status during the first trimester can potentially be addressed by improving access to pregnancy testing[3, 4]. However, little is known about how often women use pregnancy self-tests or the characteristics of these women. Understanding the characteristics of women who use pregnancy self-tests can facilitate more targeted efforts to improve pregnancy testing experiences and entry into the ANC pathway. In this study, our primary objective was to determine the prevalence of pregnancy self-testing and associated factors among pregnant women attending maternal and child health $(\mathrm{MCH})$ clinics in western Kenya. In a secondary objective, we evaluated whether pregnancy self-testing was associated with early ANC initiation among pregnant women.

\section{Methods}

\section{Study design}

From December 2018 to July 2019, we collected data as part of a baseline survey among pregnant women enrolling in the PrEP Implementation for Mothers in Antenatal Care (PrIMA) study. PrIMA is a cluster randomized trial (NCT03070600) that compares facility-based approaches for delivering oral preexposure prophylaxis (PrEP) in pregnancy. Briefly, between January 2018 and July 2019, study 
participants were recruited from women presenting for ANC in 20 public health facilities in Homabay and Siaya counties in western Kenya. In this region, approximately more than $95 \%$ of pregnant women receive antenatal care from a skilled provider[2]. Health facilities eligible for inclusion in the PrIMA study were located in counties with an HIV prevalence of at least $20 \%$, had more than $350 \mathrm{HIV}$-negative clients receiving ANC annually, and provided postnatal care services, including infant immunizations. Women were eligible for enrollment if they were: (1) pregnant, (2) HIV negative (based on test results abstracted from the $\mathrm{MCH}$ card), (3) not currently using PrEP, (4) 15 years of age, (5) TB negative and (6) planned to receive postnatal and infant care at the enrollment facility. Participants were recruited for the study while waiting to access ANC services at any ANC visit and at any gestational age. The study team administered the enrollment questionnaire in English, Kiswahili, or the local language, Dholuo (see supplementary file). Participants answered questions on socio-demographics, medical and pregnancy history, and partner characteristics. Additional details on the PrIMA study protocol are described elsewhere[5].

\section{Study variables}

We analyzed two dependent variables: "obtained pregnancy self-test from pharmacy" and "early ANC initiation." If a woman reported using a pregnancy test on her own to confirm her pregnancy and obtained the pregnancy test from the pharmacy, we categorized her as having obtained a pregnancy self-test from the pharmacy. We defined "early ANC initiation" as starting ANC during the first trimester of pregnancy (gestational age less than 13 weeks). We analyzed variables that we hypothesized from the literature would be associated with pregnancy self-test use and early ANC: socio-demographics (age, partner status, number of years in school, partner's education level, and history of prior pregnancy), accessibility (travel time to the health facility), affordability (women's employment status) and women's knowledge or attitudes (history of pregnancy or delivery complications) [3, 4, 6-9]. We analyzed "obtained pregnancy self-test from pharmacy" as an independent variable when evaluating factors associated with early ANC initiation $[3,4]$. We categorized age into three groups: $15-19$ years, $20-24$ years, and $>25$ years. We included three different age groups because adolescents and young women face unique challenges in pregnancy and are likely to have different health-seeking behaviors[10]. We defined and categorized partner status into two groups: having a partner (including a married partner) or not having a partner in the last three months at the time of the survey. The number of years in school was categorized into three groups ( 8 years, $9-12$ years, and $>12$ years), reflecting the number of years that individuals have typically spent in school at primary, secondary, and college levels in the region. We categorized the partner's education level into four groups: primary school and below (no formal schooling or having attended or completed primary school), secondary school (having attended or completed secondary school), and college (having attended or completed college). We defined history of prior pregnancy as a woman reporting that she had previously been pregnant. Women reported estimated travel time to the health facility in minutes which we categorized into two groups ( 30 minutes versus $>30$ minutes) based on the median travel time. Women were categorized as employed if they reported currently having regular employment. Women had a history of prior pregnancy or delivery complications if they indicated that they 
had the following problems during her last pregnancy: late pregnancy bleeding, miscarriage, fetal miscarriage, high blood pressure, laceration, hemorrhage, obstructed labor, premature birth (<37 weeks), spontaneous fetal death ( $<20$ weeks) or stillbirth. All variables were self-reported.

\section{Statistical analysis}

We conducted a descriptive analysis of the independent (age, partner status, history of prior pregnancy, employment status, and the number of years in school) and dependent variables (obtained pregnancy self-test from pharmacy and early ANC initiation). We examined the sources of pregnancy self-tests and the reasons for non-use of pregnancy self-tests among pregnant women. We conducted bivariate logistic regression analyses to examine the associations between the independent variables and each of the two dependent variables. In the multivariable logistic regression analysis, we excluded age and number of years in school because they were strongly correlated with a history of prior pregnancy and partner's education level, respectively (Cramer's $V>0.30, p<0.05$ )[11]. To maintain the sample size, we excluded history of pregnancy or delivery complications because we could only determine this variable among women who had previously been pregnant. We included women who reported not having a partner as a separate category under the partner's education level. We used the Mantel-Haenszel test of homogeneity to identify potential modifiers of the relationship between obtaining a pregnancy self-test from a pharmacy and early ANC initiation. The relationship differed significantly by partner's education level; therefore, we stratified the analysis by this variable. Given that we conducted a secondary analysis of data from an existing cluster randomized trial, we adjusted for the 20 facility clusters using a robust method of standard errors. Overall, $93 \%$ of records had complete data. Missingness ranged from $0.6 \%$ to $4.6 \%$ across all variables. Statistical analyses were performed using R software (R-Studio Version 1.1.456) and STATA 16.1 (College Station, TX).

\section{Ethics}

The Kenyatta National Hospital (P73/02/2017) and the University of Washington (STUDY00000438) institutional review boards approved this study. All participants provided written informed consent to participate in the study.

\section{Results}

\section{Socio-demographic characteristics}

From December 10th, 2018, to July 31st, 2019, 1128 women enrolled in the PrIMA study and completed the baseline survey. We excluded six records where the participants reported presenting for ANC earlier than the trimester in which they confirmed their pregnancy. Overall, this analysis included 1122 pregnant women between the ages of 15-43 years with a median age of 24 years (interquartile range [IQR]: 21-28 
years). At the time of the survey, the majority of women were married or had partners (92\%), had previously been pregnant (78\%), were employed (87\%), and had completed up to 12 years of school (84\%).

\section{Prevalence and correlates of pregnancy self-testing}

Table 1 summarizes the characteristics of pregnant women who confirmed their pregnancy with or without obtaining a pregnancy self-test from a pharmacy. Seventeen percent of women reported obtaining a pregnancy self-test from a pharmacy to confirm their pregnancy. An additional $5 \%$ of women reported using a pregnancy self-test and obtained their kits from a public health facility $(n=36)$, a private health facility $(n=17)$, and other sources including community health workers, school, and home $(n=4)$. Of the 846 respondents who did not use a self-test: $85 \%$ confirmed their pregnancies at a public health facility, $8 \%$ at a private health facility, and $7 \%$ used other means. Among women who reported using other means to confirm their pregnancies: 43 stated that they did not confirm their pregnancies or knew they were pregnant based on physical signs of pregnancy, including missed periods, fatigue, nausea, and abdominal growth, eight went to traditional birth attendants, community health workers or a midwife and two went to an unspecified health facility. The most frequent reasons for non-use of pregnancy self-tests included: not thinking it was necessary (58\%), lack of knowledge on self-tests (25\%), and lack of money to pay for a self-test (11\%). 
Table 1: Characteristics of pregnant women who confirmed their pregnancy with or without obtaining a pregnancy self-test from a pharmacy

Variables

Obtained a pregnancy self-test from the

pharmacy

$$
\mathrm{N}=187^{*}
$$

$\mathbf{N}$

Maternal age

$\begin{array}{llll}15-19 & 18 & (10) & 131 \\ 20-24 & 76 & (42) & 352 \\ 25 & 86 & (48) & 382\end{array}$

Number of years in school

$\begin{array}{llll}8 & 43 & (23) & 397 \\ 9-12 & 79 & (43) & 388 \\ >12 & 63 & (34) & 108\end{array}$

History of prior

pregnancy

Yes

No

Partner status

Have a partner or married

No partner

Currently employed

$$
\text { Yes }
$$

No

Travel time to the health

facility (minutes)

30

30

Partner's education

level

Primary school and

below

Secondary school

College

History of pregnancy or

delivery complications
Yes
No
13
117

(10)

(90)

(76)

524

369
(21)

186

824

(92)

0.937

p-value

0.193

74

(8) $<0.001$
0.02

$<0.001$

(

\section{Timing of presentation}

for ANC

$\begin{array}{lccc}\text { 1st trimester } & 80 & (43) & 292 \\ \text { 2nd trimester } & 98 & (52) & 528 \\ \text { 3rd trimester } & 9 & (5) & 82\end{array}$

0.009

* The number of respondents for each variable may vary due to missing responses. 
Table 2 shows the univariate and multivariable logistic regression results for correlates of pregnancy selftest use. In the univariate analysis, women who obtained a pregnancy self-test from the pharmacy were more likely to be pregnant for the first time, employed, more educated $(9-12$ years or $>25$ years vs. 8 years), spend 30 minutes or less traveling to the health facility, and have more educated partners (secondary school or college vs. primary school or below). In the multivariable analysis, women who obtained a pregnancy self-test from the pharmacy were more likely to be employed, spend 30 minutes or less traveling to the health facility, and have more educated partners (secondary school or college vs. primary school or below). Obtaining a pregnancy self-test from the pharmacy was not associated with a history of a prior pregnancy. 
Table 2: Univariate and multivariable logistic regression examining the variables associated with obtaining a pregnancy self-test from a pharmacy

Variables

Univariate Model

OR $(95 \% \mathrm{CI})$

$\mathrm{p}$-value

Multivariable Model

Partner status

Have a partner or married

No partner

History of prior pregnancy

Yes

No

$1.02(0.46$

0.954

2.26)

Reference

group

Reference

group

Reference

$1.52(1.13$

2.06)

group

$1.70)$

Age

$\begin{array}{lll}15-19 & 0.61(0.35, & 0.087 \\ 20-24 & 1.07) & 0.96(0.59, \\ & 1.55) & 0.87 \\ 25 & \text { Reference } & \\ & \text { group } & \end{array}$

Currently employed

Yes

No

$2.88(2.08, \quad<0.0001$

2.01 (1.31,

0.001

3.97)

3.08)

Reference

Reference

group group

Number of years in school

8 years

9 - 12 years

$>12$ years

Travel time to health facility(minutes)

30

$>30$

Partner's education level

Primary school and below

Secondary school

College

No partner

Reference

group

$\begin{array}{ll}1.87(1.30, & 0.001 \\ 2.71) & \\ 5.39(2.74, & <0.0001 \\ 10.57) & \end{array}$

$2.19(1.40, \quad 0.001 \quad 1.81(1.19, \quad 0.005$

3.42)

2.73)

Reference Reference

group

group

Reference Reference

group

group

$3.22(1.66, \quad 0.001 \quad 3.11(1.63,0.001$

6.27)

$5.93)$

$7.17(3.92, \quad<0.0001$

$6.11(3.40, \quad<0.0001$

13.11)

10.96)

$2.71(1.22$,

$6.00)$

0.251

p-value 
Approximately $65 \%$ of women confirmed their pregnancy in the first trimester. However, only $35 \%$ of the women initiated ANC early - in the first 13 weeks of pregnancy. Fifty-eight percent of the women started ANC during the second trimester, and $8 \%$ during the third trimester.

Table 3 shows the univariate logistic regression results for correlates of early ANC initiation. In the univariate analysis, women who initiated ANC early were more likely to have obtained a pregnancy selftest from a pharmacy, be pregnant for the first time, be employed, and have a more educated partner(college vs. primary school or below). Table 4 shows the multivariable logistic regression results stratified by partner education level. Early ANC initiation was more likely among women with collegeeducated partners if the women obtained a pregnancy self-test from a pharmacy (OR: 1.94, 95\% Cl: 1.12, 3.35). However, early initiation among women with partners who had at least a primary level education was less likely if the women obtained a pregnancy self-test from a pharmacy (OR:0.25, 95\% Cl: 0.068 , 0.92). Among women with partners who had at least a primary or secondary level education, early ANC initiation remained more likely if women were pregnant for the first time. 
Table 3: Univariate logistic regression examining the variables associated with early ANC initiation

Variables

Obtained pregnancy self-test from pharmacy Yes

No

\section{Partner status}

Have a partner or married

No partner

OR (95\% CI)

p-value

$1.56(1.12,2.17) \quad 0.008$

Reference group

$0.67(0.42,1.09)$

0.105

Reference group

History of prior pregnancy

Yes

No

Age

$15-19$

$20-24$

25

Currently employed

Yes

No

Number of years in school 8 years

Reference group

$1.55(1.12,2.13)$

0.008

$0.95(0.65,1.38)$

0.791

$1.24(0.98,1.57)$

0.079

Reference group

9 - 12 years

$1.33(1.01,1.75)$

0.043

Reference group

Reference group

$1.23(0.97,1.55)$

0.091

$>12$ years

$1.52(0.96,2.41)$

0.077

Travel time to health facility(minutes)

30 $>30$

\section{Partner's education level}

Primary school and below

Secondary school

College

No partner

History of pregnancy or delivery complications

Yes

No
$0.80(0.55,1.16)$

Reference group

Reference group

$1.30(1.00,1.68)$

$2.04(1.56,2.67)$

$<0.0001$

$1.35(0.77,2.37)$

Reference group
0.054

0.239

$-$

0.300 
Table 4: Logistic regression examining the variables associated with early ANC initiation and stratified by partner's education level

\begin{tabular}{|c|c|c|c|c|c|c|}
\hline \multirow{4}{*}{$\begin{array}{l}\text { Variables } \\
\text { Obtained pregnancy self-test } \\
\text { from pharmacy }\end{array}$} & \multicolumn{6}{|c|}{ Partner's education level } \\
\hline & \multicolumn{2}{|c|}{$\begin{array}{c}\text { Primary school and } \\
\text { below } \\
(\mathrm{N}=327)\end{array}$} & \multicolumn{2}{|c|}{$\begin{array}{l}\text { Secondary school } \\
(\mathrm{N}=406)\end{array}$} & \multicolumn{2}{|c|}{$\begin{array}{c}\text { College } \\
(\mathbf{N}=247)\end{array}$} \\
\hline & OR (95\% CI) & $\begin{array}{l}\text { p- } \\
\text { value }\end{array}$ & $\begin{array}{l}\text { OR }(95 \% \\
\text { CI })\end{array}$ & $\begin{array}{l}\text { p- } \\
\text { value }\end{array}$ & $\begin{array}{l}\text { OR }(95 \% \\
\text { CI) }\end{array}$ & $\begin{array}{l}\text { p- } \\
\text { value }\end{array}$ \\
\hline & & & & & & \\
\hline Yes & $\begin{array}{l}0.25(0.068, \\
0.92)\end{array}$ & 0.036 & $\begin{array}{l}0.92(0.57 \\
1.50)\end{array}$ & 0.749 & $\begin{array}{l}1.94 \\
(1.12, \\
3.35)\end{array}$ & 0.018 \\
\hline No & $\begin{array}{l}\text { Reference } \\
\text { group }\end{array}$ & & & & & \\
\hline History of prior pregnancy & & & & & & \\
\hline Yes & $\begin{array}{l}\text { Reference } \\
\text { group }\end{array}$ & & & & & \\
\hline No & $\begin{array}{l}2.36(1.23 \\
4.51)\end{array}$ & 0.009 & $\begin{array}{l}2.04(1.12, \\
3.71)\end{array}$ & 0.019 & $\begin{array}{l}0.89 \\
(0.54 \\
1.48)\end{array}$ & 0.654 \\
\hline Currently employed & & & & & & \\
\hline Yes & $\begin{array}{l}2.03(0.76 \\
5.44)\end{array}$ & 0.157 & $\begin{array}{l}1.11(0.57, \\
2.16)\end{array}$ & 0.752 & $\begin{array}{l}0.95 \\
(0.47 \\
1.89)\end{array}$ & 0.879 \\
\hline No & $\begin{array}{l}\text { Reference } \\
\text { group }\end{array}$ & & & & & \\
\hline $\begin{array}{l}\text { Travel time to health } \\
\text { facility(minutes) }\end{array}$ & & & & & & \\
\hline 30 & $\begin{array}{l}1.20(0.88, \\
1.63)\end{array}$ & 0.251 & $\begin{array}{l}0.95(0.55, \\
1.64)\end{array}$ & 0.858 & $\begin{array}{l}1.19 \\
(0.59 \\
2.39)\end{array}$ & 0.621 \\
\hline$>30$ & $\begin{array}{l}\text { Reference } \\
\text { group }\end{array}$ & & & & & \\
\hline
\end{tabular}

\section{Discussion}

In this study, we investigated the prevalence and correlates of pregnancy self-testing among pregnant women attending $\mathrm{MCH}$ clinics in western Kenya. Overall, the prevalence of pregnancy self-testing in the study population was low, with $23 \%$ of women reporting having used a pregnancy self-test to confirm their pregnancy and $17 \%$ of women having obtained a pregnancy self-test from a pharmacy to confirm their pregnancy. We report a slightly lower prevalence of pregnancy self-test use than a 2006 South African study in which $27 \%$ of ANC clients obtained a pregnancy self-test from a private pharmacy[4]. Interestingly, most women who did not use a pregnancy self-test either did not think it was necessary or did not know that they could use one. Further studies are needed to understand women's knowledge and attitudes toward pregnancy self-testing.

In this study population, employment, education level, partner's education level, and travel time to health facility were the strongest correlates of pregnancy self-testing. Employed women may have greater 
autonomy in deciding how to spend financial resources than women who are not employed. Women who are more educated are more likely to have increased knowledge and familiarity with obtaining and using pregnancy tests[9]. Women with more educated partners might be likely to experience positive reinforcement of pregnancy testing behaviors and have the financial resources for pregnancy selftests[12]. Finally, women who reported shorter travel times might be more likely to afford pregnancy selftests or live in urban areas with better access to pregnancy self-tests[13]. Our findings are consistent with studies conducted in the United States that demonstrate increased rates of pregnancy self-test use among women of higher socioeconomic status[9].

In this study population, we found that $35 \%$ of women reported initiating ANC in the first trimester of pregnancy. This proportion is higher compared to findings reported for sub-Saharan Africa (24.9\%) in a 2017 systematic review[14] and for the greater study region (<20\%) in the 2014 Kenya Demographic and Health Survey[2]. In the univariate analysis, we found that women who initiated ANC in the first trimester were more likely to obtain a pregnancy self-test from the pharmacy, have no history of prior pregnancy, be employed, and have a college-level educated partner. Interestingly, in the stratified analysis, we found that partner education level modified the association between obtaining a pregnancy self-test from the pharmacy and early ANC initiation. In cases where partners had a college-level education, women were twice as likely to initiate ANC early if they obtained a pregnancy self-test from a pharmacy. However, in cases where partners had a primary school education or below, women were less likely to start ANC early if they obtained a pregnancy self-test from a pharmacy. Prior studies show that a partner's education level is an essential determinant of women's health-seeking behavior $[15,16]$. When partners are more educated, women are likely to live in households of higher socioeconomic status and able to forgo the opportunity costs of initiating ANC early[12].

To our knowledge this is one of the few studies to evaluate whether pregnancy testing is associated with early ANC initiation. One study in Ethiopia found that women who recognized their pregnancy using a urine test were more likely to initiate ANC early than women who used other means such as missed periods $[17,18]$. A prior study in South Africa found that women who independently decided to obtain a urine pregnancy test from a private pharmacy initiated ANC 3.6 weeks earlier in their pregnancy[4]. However, neither of these studies adjusted for partner education level; a recent systematic review from sub-Saharan Africa shows that studies did not evaluate the relationship between partner education and early ANC initiation[7]. Our study shows that pregnancy testing is an important prerequisite to initiating ANC early, particularly among women with highly educated partners. Strategies that increase knowledge and understanding of ANC and its benefits, bring care closer to the community, or provide financial and social support are important components to realizing the full benefits of pregnancy testing. For example, community-based models of care that combine the delivery of free pregnancy tests and home-based counseling could be a promising strategy for improving early ANC initiation[19, 20]. Exploring 
opportunities to engage community pharmacies, which are known to be frequently accessed[21] and sell pregnancy tests[22], could also expand the options available to women for early pregnancy recognition and referral to $\mathrm{ANC}[23]$.

Our study has some limitations. Although we were able to recruit over 1000 study participants from 20 clinics in western Kenya, the majority of the participants came from rural areas therefore some aspects of our findings may not generalize to other settings. Secondly, participants self-reported when they confirmed their pregnancy and when they first presented for antenatal care. It is therefore possible that some women may not accurately recall their pregnancy history leading to over- or underestimation of study outcomes. Thirdly, because our sample comprised women attending ANC as part of a PrEP implementation trial in public-sector $\mathrm{MCH}$ clinics, our findings may not be representative of all ANC attendees who use pregnancy self-tests in this setting. Finally, given that we conducted a cross-sectional analysis of enrollment data from an implementation trial, we were unable to assess additional independent variables such as knowledge and attitudes toward pregnancy self-testing and ANC[4].

\section{Conclusions}

In conclusion, this study confirms that pregnancy testing plays a beneficial role in facilitating early ANC initiation. However, we found modest overall use of pregnancy self-tests among women attending ANC in western Kenya. Most women either did not see the utility of pregnancy self-testing or did not know about pregnancy self-tests. Further research is needed to understand women's attitudes, knowledge, and motivations toward pregnancy self-testing and how it informs decision-making around ANC attendance. To create value for women in the ANC pathway, we need to explore strategies to adapt existing community-based models that include pregnancy testing, antenatal counseling, and timely referral for care.

\section{Declarations}

\section{Acknowledgements}

We thank the PrEP Implementation for Mothers in Antenatal Care (PrIMA) study team and clients for their contributions to this study; we thank the Homa Bay and Siaya County Directors of Health for their support.

\section{References}

1. Tunçalp Ö, Pena-Rosas JP, Lawrie T, Bucagu M, Oladapo OT, Portela A, et al. WHO recommendations on antenatal care for a positive pregnancy experience-going beyond survival. BJOG: An International Journal of Obstetrics \& Gynaecology. 2017;124(6):860-2. 
2. KNBS. Kenya demographic and health survey, 2014. Calverton, MD: Kenya National Bureau of Standards; 2014.

3. Pell C, Meñaca A, Were F, Afrah NA, Chatio S, Manda-Taylor L, et al. Factors affecting antenatal care attendance: results from qualitative studies in Ghana, Kenya and Malawi. PloS one. 2013;8(1):e53747.

4. Morroni C, Moodley J. The role of urine pregnancy testing in facilitating access to antenatal care and abortion services in South Africa: a cross-sectional study. BMC Pregnancy and Childbirth. 2006;6(1):26.

5. Dettinger JC, Kinuthia J, Pintye J, Mwongeli N, Gómez L, Richardson BA, et al. PrEP Implementation for Mothers in Antenatal Care (PrIMA): study protocol of a cluster randomised trial. BMJ open. 2019;9(3):e025122.

6. Magadi MA, Madise NJ, Rodrigues RN. Frequency and timing of antenatal care in Kenya: explaining the variations between women of different communities. Social science \& medicine. 2000;51(4):551-61.

7. Okedo-Alex IN, Akamike IC, Ezeanosike OB, Uneke CJ. Determinants of antenatal care utilisation in sub-Saharan Africa: a systematic review. BMJ open. 2019;9(10):e031890.

8. Simkhada B, Teijlingen ERv, Porter M, Simkhada P. Factors affecting the utilization of antenatal care in developing countries: systematic review of the literature. Journal of advanced nursing. 2008;61(3):244-60.

9. Jeng LL, Moore Jr RM, Kaczmarek RC, Placek PJ, Bright RA. How frequently are home pregnancy tests used? Results from the 1988 National Maternal and Infant Health Survey. Birth. 1991;18(1):11-3.

10. Atuyambe L, Mirembe F, Tumwesigye NM, Annika J, Kirumira EK, Faxelid E. Adolescent and adult first time mothers' health seeking practices during pregnancy and early motherhood in Wakiso district, central Uganda. Reproductive health. 2008;5(1):1-11.

11. Akoglu H. User's guide to correlation coefficients. Turkish journal of emergency medicine. 2018;18(3):91-3.

12. Adjiwanou V, Bougma M, LeGrand T. The effect of partners' education on women's reproductive and maternal health in developing countries. Social Science \& Medicine. 2018;197:104-15.

13. Wafula F, Abuya T, Amin A, Goodman C. Availability and dispensing practices for antimalarials and antimicrobials in western Kenyan pharmacies. Pharm Reg Affairs. 2013;2(1):1-8.

14. Moller A-B, Petzold M, Chou D, Say L. Early antenatal care visit: a systematic analysis of regional and global levels and trends of coverage from 1990 to 2013. The Lancet Global Health. 2017;5(10):e977- 
e83.

15. Adewuyi EO, Auta A, Khanal V, Bamidele OD, Akuoko CP, Adefemi K, et al. Prevalence and factors associated with underutilization of antenatal care services in Nigeria: A comparative study of rural and urban residences based on the 2013 Nigeria demographic and health survey. PloS one. 2018;13(5):e0197324.

16. Ousman SK, Mdala I, Thorsen VC, Sundby J, Magnus JH. Social determinants of antenatal care service use in Ethiopia: changes over a 15-year span. Frontiers in public health. 2019;7:161.

17. Tesfaye G, Loxton D, Chojenta C, Semahegn A, Smith R. Delayed initiation of antenatal care and associated factors in Ethiopia: a systematic review and meta-analysis. Reproductive health. 2017;14(1):117.

18. Gudayu TW, Woldeyohannes SM, Abdo AA. Timing and factors associated with first antenatal care booking among pregnant mothers in Gondar Town; North West Ethiopia. BMC Pregnancy and Childbirth. 2014;14(1):287.

19. Andersen K, Singh A, Shrestha MK, Shah M, Pearson E, Hessini L. Early pregnancy detection by female community health volunteers in Nepal facilitated referral for appropriate reproductive health services. Global Health: Science and Practice. 2013;1(3):372-81.

20. Comfort AB, Juras RC, Bradley SE, Ranjalahy Rasolofomanana J, Noeliarivelo Ranjalahy A, Harper CC. Do home pregnancy tests bring women to community health workers for antenatal care counselling? A randomized controlled trial in Madagascar. Health policy and planning. 2019;34(8):566-73.

21. Wafula FN, Miriti EM, Goodman CA. Examining characteristics, knowledge and regulatory practices of specialized drug shops in Sub-Saharan Africa: a systematic review of the literature. BMC health services research. 2012;12(1):223.

22. Kolesar RJ, Audibert M, Comfort AB. Cost-effectiveness analysis and mortality impact estimation of scaling-up pregnancy test kits in Madagascar, Ethiopia and Malawi. Health policy and planning. 2017;32(6):869-81.

23. Dillip A, Kimatta S, Embrey M, Chalker JC, Valimba R, Malliwah M, et al. Can formalizing links among community health workers, accredited drug dispensing outlet dispensers, and health facility staff increase their collaboration to improve prompt access to maternal and child care? A qualitative study in Tanzania. BMC health services research. 2017;17(1):416.

\section{Supplementary Files}

This is a list of supplementary files associated with this preprint. Click to download. 
- Appendix.docx

Page 17/17 